\title{
Study on the rheology of coal-oil slurries during heating at high pressure
}

\author{
Bingfeng $\operatorname{Yan}^{1,2}$
}

Received: 18 January 2017/Revised: 13 May 2017 / Accepted: 21 June 2017/Published online: 27 June 2017

(C) The Author(s) 2017. This article is an open access publication

\begin{abstract}
Using the self-developed viscosity measuring device, the viscosity variations of coal-oil slurries with temperature increasing during coal-oil co-processing were studied. The results show that the viscosity of coal-oil slurries prepared by different kinds of oil varies differently during heating. The viscosity of the coal-oil slurry prepared by the catalytic cracking slurry (FCC) generally decreases during heating. However, the viscosity of the coal-oil slurry prepared by the high-temperature coal tar (CT) will peak at $338^{\circ} \mathrm{C}$ during heating. The differences in viscosity variations of coal-oil slurries are analyzed. In addition to the temperature, the properties of the solvents and coal are the main influencing factors. Because the used coal contains a large number of polar functional groups, the swelling behavior of the coal in polar solvent (CT) is stronger than that in non-polar solvent (FCC). The swelling effect of the coal can result in the appearance of the viscosity peak. Therefore, before $100{ }^{\circ} \mathrm{C}$, the solvent molecules entering into the coal pores is the main influencing factor of coal-oil slurries viscosity variations. After $100{ }^{\circ} \mathrm{C}$, the increasing of particle size of coal particles is the main influencing factor of coal-oil slurries viscosity variations.
\end{abstract}

Keywords Coal-oil slurry $\cdot$ Rheology $\cdot$ Swelling $\cdot$ High temperature and pressure

\section{Introduction}

In coal-oil co-processing, the temperature of coal-oil slurry after heating by the preheater is generally up to $380-400{ }^{\circ} \mathrm{C}$. The coal will decompose and generate a large amount of free radicals during heating. The free radicals are very unstable. If there is sufficient active hydrogen, the free radicals can combine with the active hydrogen to generate small molecular substances. The small molecular substances can reduce the viscosity of coal-oil slurry. However, if the active hydrogen is insufficient, the free

Bingfeng Yan

yanbingfeng198415@foxmail.com

1 State Key Laboratory of Coal Mining and Clean Utilization, Beijing 100013, China

2 Beijing Research Institute of Coal Chemistry, China Coal Research Institute, Beijing 100013, China radicals themselves will aggregate to produce macromolecular substances. The macromolecular substances can increase the viscosity of coal-oil slurry. Generally, the viscosity of coal-oil slurry changes significantly during heating. Viscosity is an important parameter of the preheater design. Viscosity is also important to determine the flow status of slurry and to calculate pressure drop and heat transfer. Therefore, it is necessary to study the viscosity variations of coal-oil slurry during heating at high pressure. The study on the viscosity variations of coal-oil slurries is mainly in direct coal liquefaction (Okutani et al. 1984; Tsutsumi and Yoshida 1986; Deng et al. 1987; Xiong et al. 2009). However, in coal-oil co-processing, the study on the viscosity variations of oil-coal-oil slurries is little (Xue et al. 2013; Gao et al. 2015). In this paper, the viscosity variations of coal-oil slurries during heating were studied by a self-developed viscosity measuring device, and the reasons for the changes of viscosity of coal-oil slurries were analyzed. 


\section{Experimental}

A low rank bituminous coal from Xinjiang was used. Its properties are listed in Table 1. Two kinds of oil were used. One is high-temperature coal tar from Xinjiang, marked CT. The other is the catalytic cracking slurry from Shanghai Petrochemical Company, marked FCC. Their properties are listed in Table 2. Iron based catalyst was used. The addition amount of catalyst is $1 \%$ of the weight of coal and oil.

\section{Measuring apparatus and method}

\subsection{Measuring apparatus}

The self-developed viscosity measuring apparatus (Fig. 1) is mainly composed of a 0.5 -liter autoclave, a stirring unit and a torque measuring unit. Autoclave can simulate the heating process of the co-processing, the stirring unit is to prevent the deposition of coal particles, and the torque measuring unit is to record the torque changes of the coaloil slurry. Torque changes can reflect the viscosity variations of coal-oil slurry.

\subsection{Power number method}

For a stirring device, there is only one power curve. If the swirl phenomenon is not obvious, the relationship between Power number $\left(P_{\mathrm{o}}\right)$ and Reynolds number $(R e)$ is as follows (Wu et al. 2007):

$P_{o}=K R e^{x}$

where, $K$ is the overall shape factor of the system geometry, $x$ is a parameter. According to the definition of Power number $\left(P_{\mathrm{o}}\right)$ and Reynolds number $(R e)$, there are the following formulas:

$$
\begin{aligned}
& P_{o}=N / \rho n^{3} D^{5} \\
& R e=D^{2} n \rho / \mu \\
& N=2 \pi M n
\end{aligned}
$$

where, $N$ is the stirring power, $\rho$ is the density, $n$ is the rotating speed, $D$ is the diameter of impeller, $\mu$ is the viscosity, $M$ is the torque.
If Eq. (2) is substituted into Eq. (1), it will get the following relationship:

$$
\begin{aligned}
& \mu=a M^{b} \\
& a=\left(\frac{2 \pi}{\rho n^{2} D^{5} K}\right)^{-\frac{1}{x}} D^{2} n \rho \\
& b=-1 / x
\end{aligned}
$$

If the viscosity of substances is known, and the torque of substances is also measured, the values of $a$ and $b$ in Eq. (3) will be determined. Then for the unknown viscosity substance, if its torque is measured, its viscosity can be calculated by Eq. (3).

\subsection{The relationship between viscosity and torque}

23 kinds of Newtonian fluids with different viscosity were used to determine the relationship between viscosity and torque. The maximum viscosity of the Newtonian fluids is $1713.7 \mathrm{mPa} \mathrm{s}$, and the minimum viscosity is $11.9 \mathrm{mPa} \mathrm{s}$. The viscosity of the 23 kinds of Newtonian fluids was measured by capillary viscometers according to GB/T 2651988. While the torques of the 23 kinds of Newtonian fluids were measured at $400 \mathrm{r} / \mathrm{min}$ using the self-developed measuring apparatus (Fig. 1). The viscosity-torque curves of the 23 kinds of Newtonian fluids are shown in Fig. 2. The viscosity-torque correlations are shown in Table 3 . $R e \leq 36$, there is a linear relationship between viscosity and torque; $R e>36$, the relationship between viscosity and torque is in accordance with the power law equation. The mean fit relative deviation is no more than $3.73 \%$, which has a good fitting result.

\section{Results and discussion}

\subsection{Viscosity of coal-oil slurries}

The viscosity of coal-oil slurries during heating was measured under the initial hydrogen pressure of $12.3 \mathrm{MPa}$.

\begin{tabular}{|c|c|c|c|c|c|c|c|c|c|}
\hline \multicolumn{4}{|c|}{ Proximate $(\%)$} & \multicolumn{5}{|c|}{ Ultimate (daf \%) } & \multirow[t]{2}{*}{$\mathrm{H} / \mathrm{C}$} \\
\hline$M_{\mathrm{ad}}$ & $A_{\mathrm{d}}$ & $V_{\text {daf }}$ & $\mathrm{FC}_{\mathrm{daf}}$ & $\mathrm{C}$ & $\mathrm{H}$ & $\mathrm{O}$ & $\mathrm{N}$ & S & \\
\hline 10.34 & 6.05 & 49.55 & 50.45 & 76.71 & 5.44 & 15.81 & 1.64 & 0.40 & 0.85 \\
\hline
\end{tabular}
The results are shown in Fig. 3.

As the temperature increasing, the viscosity variations of coal-oil slurry prepared by CT can be divided into three stages. The first, when temperature is less than $100{ }^{\circ} \mathrm{C}$, the

Table 1 Proximate and ultimate analysis of the coal

Note $M_{\mathrm{ad}}$ is the air-dried basis moisture of the coal, and $A_{\mathrm{d}}$ is the dry basis ash of the coal, and $V_{\mathrm{daf}}$ is the dry-ash free basis volatile matter of the coal, and $\mathrm{FC}_{\mathrm{daf}}$ is the dry-ash free basis fixed carbon of the coal 
Table 2 The properties of CT and FCC

\begin{tabular}{|c|c|c|c|c|c|c|c|c|c|}
\hline Category & $\rho\left(20^{\circ} \mathrm{C}\right)\left(\mathrm{g} / \mathrm{cm}^{3}\right)$ & $\eta\left(60^{\circ} \mathrm{C}\right)(\mathrm{mPa} \mathrm{s})$ & Saturate $(\%)$ & Aromatic (\%) & $\operatorname{Resin}(\%)$ & Asphaltene (\%) & TI $(\%)$ & $\mathrm{H} / \mathrm{C}$ & $\bar{f}$ \\
\hline CT & 1.1690 & 73 & 0.00 & 21.18 & 43.04 & 32.29 & 3.49 & 0.75 & 0.90 \\
\hline FCC & 1.1088 & 1212 & 9.54 & 68.46 & 19.54 & 2.37 & 0.09 & 0.96 & 0.72 \\
\hline
\end{tabular}

Note TI is the Toluene insoluble. $f_{a}$ is the aromatic carbon ratio, and was calculated on ${ }^{1} \mathrm{H}-\mathrm{NMR}$ spectra and elemental composition

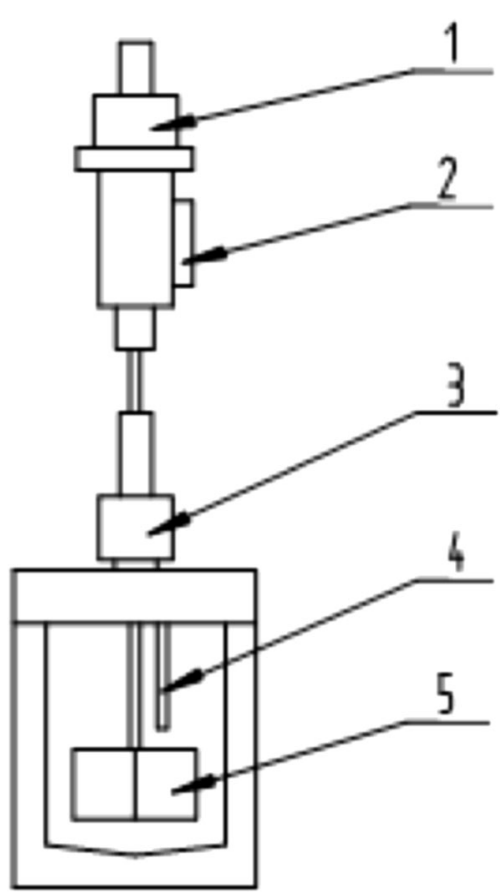

Fig. 1 Viscosity measuring apparatus 1 -torque meter; 2-electronic coupling meter; 3 - outer magnetic jar; 4-thermocouple; 5 stirring impeller

viscosity decreases rapidly with temperature increasing. The second, when temperature is between 100 and $320^{\circ} \mathrm{C}$, the viscosity is almost constant. The third, when temperature is more than $320^{\circ} \mathrm{C}$, the viscosity increases sharply, and reaches a maximum at $338^{\circ} \mathrm{C}$. The maximum at $338{ }^{\circ} \mathrm{C}$ is $3156.4 \mathrm{mPa} \mathrm{s}$, then the viscosity decreases rapidly, and after $390{ }^{\circ} \mathrm{C}$, the viscosity is less than $10 \mathrm{mPa}$.

As the temperature increasing, the viscosity variations of coal-oil slurry prepared by FCC can be divided into two stages. The first, when temperature is less than $160{ }^{\circ} \mathrm{C}$, the viscosity decreases rapidly with temperature increasing. The second, when temperature is more than $160{ }^{\circ} \mathrm{C}$, the viscosity decreases slowly with temperature increasing.

From Fig. 3, it can be seen that the viscosity variations of coal-oil slurry prepared by FCC is different from that prepared by CT. When temperature is less than $100{ }^{\circ} \mathrm{C}$, the viscosity of the two kinds of coal-oil slurries differ by
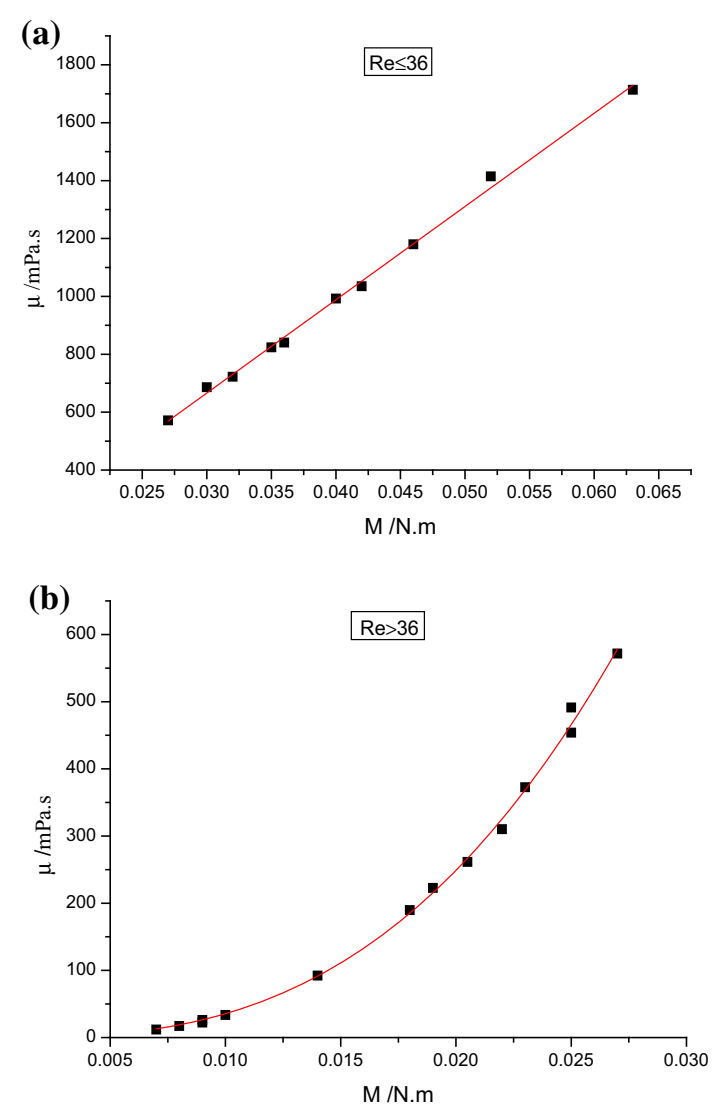

Fig. 2 The viscosity-torque curve at $400 \mathrm{r} / \mathrm{min}$

more than $100 \mathrm{mPa}$ s. When temperature is between 100 and $160{ }^{\circ} \mathrm{C}$, the differences of the viscosity of coal-oil slurries are reduced to tens $\mathrm{mPa}$ s. The differences of viscosity of coal-oil slurries before $160{ }^{\circ} \mathrm{C}$ are caused by the properties of FCC and CT. The viscosity of FCC is larger than CT, so the viscosity of coal-oil slurry prepared by FCC is also larger than that prepared by CT. However, the effect of the property of oil on the viscosity variations decreases with temperature increasing. When temperature is between 160 and $240{ }^{\circ} \mathrm{C}$, the viscosity of the coal-oil slurries is almost the same. This means the properties of FCC and CT have no effect on the viscosity variations of the coal-oil slurries. This finding is consistent with Wang's findings (Wang et al. 2007). However, when temperature is more than $240{ }^{\circ} \mathrm{C}$, the effect of the property of FCC and $\mathrm{CT}$ on the viscosity variations is also significantly different. 
Table 3 The viscosity-torque correlations at $400 \mathrm{r} / \mathrm{min}$

\begin{tabular}{llllc}
\hline$R e$ & Equation & Correlation coefficient $\left(R^{2}\right)$ & Mean fit relative deviation $(\%)$ & Mean fit absolute deviation (mPa s) \\
\hline$\leq 36$ & $\mu=32222 M-300.63$ & 0.9973 & 1.31 & 13.2 \\
$>36$ & $\mu=2 \times 10^{7} \times M^{2.8926}$ & 0.9990 & 3.73 & 7.0 \\
\hline
\end{tabular}

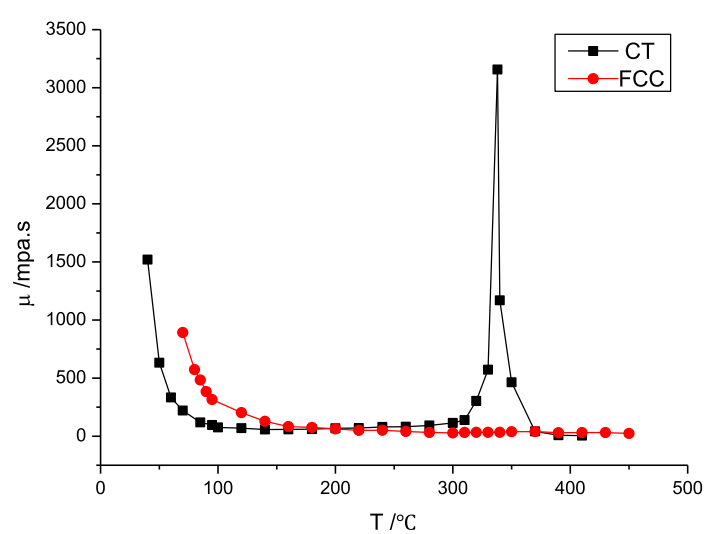

Fig. 3 Viscosity-temperature curves

\subsection{Analysis of viscosity-temperature curves}

In order to analyze the causes of the viscosity variations, it is important to know when the coal-oil slurries begin to react. Figure 4 shows the pressure changes in autoclave with temperature increasing. When $\mathrm{CT}$ is used as the solvent, and temperature is less than $280{ }^{\circ} \mathrm{C}$, the relationship between pressure and temperature is linear. That means coal-oil slurry has not yet react with hydrogen. When temperature is higher than $280{ }^{\circ} \mathrm{C}$, the pressure rises slowly, and then begins to drop as temperature increasing. That means coal-oil slurry is carrying out hydrogenation reaction. When FCC is used as the solvent, the coal-oil slurry starts hydrogenation reaction at $300{ }^{\circ} \mathrm{C}$.

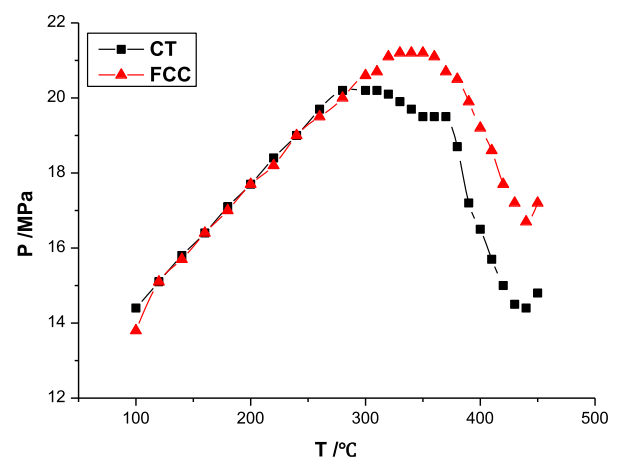

Fig. 4 The curve of pressure changes with temperature

\subsubsection{Analysis of viscosity variations before hydrogenation reaction}

It is found that the increase of viscosity of coal-oil slurry at low temperature is mainly caused by swelling (Okutani et al. 1980; Deng et al. 1989; Hao et al. 2008). According to the swelling mechanism of coal particles, the viscosity of the solvent itself and the volume fraction of coal particles are the main factors that effect on the viscosity of coal-oil slurry (Shi 2012). The viscosity variations of the solvents with temperature can be expressed by Aandrade equation (Poling 2006):

$\ln \mu_{L}=A+\frac{B}{T}$

where, $A$ and $B$ are constants related to solvent properties, $\mu_{L}$ is the solvent viscosity, $T$ is the absolute temperature.

The viscosity variations of coal-oil slurry can be expressed by Mooney formula (Mooney 1951):

$\mu_{r}=\frac{\mu_{s}}{\mu_{L}}=\exp \left(\frac{2.5 \emptyset_{V}}{1-\emptyset_{V} / \emptyset_{m}}\right)$

where, $\mu_{r}$ is the relative viscosity, $\mu_{s}$ is the slurry viscosity, $\mu_{L}$ is the solvent viscosity, $\emptyset_{v}$ is the volume fraction of solid particles, $\emptyset_{m}$ is the maximum volume fraction, 2.5 is the shape factor of spherical particles.

The Mooney formula can be changed into a logarithmic form, and combined with Aandrade equation, then a new formula will be got as follows:

$\ln \mu_{s}=\frac{2.5 \emptyset_{V}}{1-\emptyset_{V} / \emptyset_{m}}+\left(A+\frac{B}{T}\right)$

According to formula (6), if the swelling effect is little with increasing temperature, the relationship between $\ln \mu_{s}$ and $\frac{1}{T}$ is close to linear. While if the swelling effect is strong, the relationship is nonlinear. The relationship between viscosity and temperature of two kinds of coal-oil slurries is analyzed. The results are shown in Table 4 and Fig. 5.

In order to find the reasons for the viscosity variations, the viscosity of coal-oil slurries at different temperatures and time are measured, and the particle size of coal particles at different temperatures are also measured. The results are shown in Figs. 6 and 7. When FCC is used as the solvent, the viscosity variations of coal-oil slurry is mainly affected by temperature from Fig. 5, but there is a 
mutation at $100{ }^{\circ} \mathrm{C}$. This is due to the reduction of lubricated solvent. Because the molecular structures of FCC and coal are different, the swelling of coal particles is not obvious. It can be seen from Fig. 7 that the particle size of coal particles at $100{ }^{\circ} \mathrm{C}$ does not become larger than original coal particles. When FCC is used as the solvent, the particle size of coal particles at $100{ }^{\circ} \mathrm{C}$ is even smaller than original coal particles in Fig. 7. The reason is that the coal particles at $100{ }^{\circ} \mathrm{C}$ is separated by Tetrahydrofuran (THF) from coal-oil slurry. The coal particles are partially dissolved by THF. That leads to the particle size become smaller (Zhang et al. 2004). When temperature is less than $100{ }^{\circ} \mathrm{C}$, the movement of FCC solvent molecules is slow at low temperature. Therefore, the solvent molecules entering into the coal pores will need a long time. When temperature is at $70{ }^{\circ} \mathrm{C}$, the swelling equilibrium time is $96 \mathrm{~h}$ in Fig. 6. However, when temperature is at $100{ }^{\circ} \mathrm{C}$, the swelling equilibrium time is reduced to $0.5 \mathrm{~h}$. The time from room temperature up to $100{ }^{\circ} \mathrm{C}$ is about $27 \mathrm{~min}$, which is consistent with the swelling equilibrium time. Therefore, the FCC molecules entering into the coal pores leads to the appearance of mutation at $100{ }^{\circ} \mathrm{C}$.

Because CT contains a small number of small molecules, the small molecules can quickly enter into the coal pores at low temperature. That results in the first change in the relationship between $\ln \mu_{s}$ and $\frac{1}{T}$ at $60{ }^{\circ} \mathrm{C}$. Then the macromolecules of CT gradually enter into the coal pores. That results in the second change at $100{ }^{\circ} \mathrm{C}$. As temperature increasing, the solubility of $\mathrm{CT}$ to coal particles increases. The substances in the coal are constantly being dissolved, and the coal particles are expanding. It can be seen from Fig. 7 that the particle size of coal particles at $220{ }^{\circ} \mathrm{C}$ increases significantly. The substances are mainly composed of asphaltene and preasphaltene. They may play a role in viscosity increasing (Han et al. 2003).

\subsubsection{Analysis of viscosity variations in hydrogenation reaction}

When the coal samples begin pyrolysis reaction, the intermediate products such as asphaltene and preasphaltene are generated. They may affect the viscosity variations of

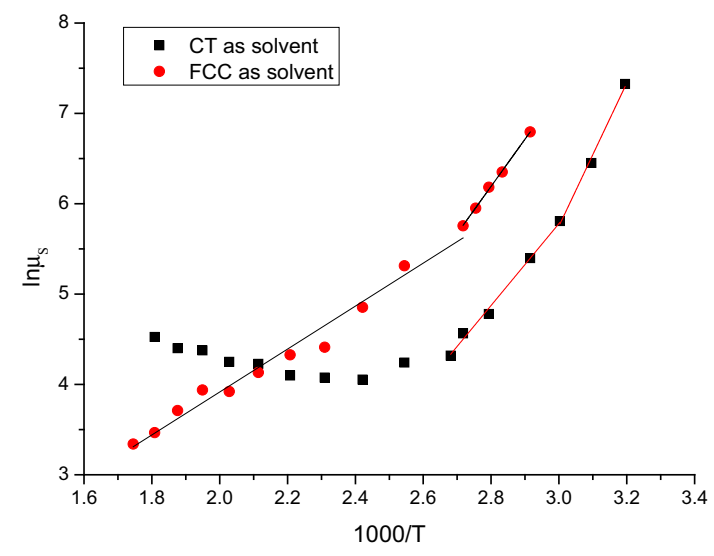

Fig. 5 The relationship curves between $\ln \mu_{s}$ and $\frac{1}{T}$



Fig. 6 Viscosity of coal-oil slurry under different swelling time

coal-oil slurries (Tsutsumi and Yoshida 1986; Sawatzky et al. 1992). In order to know the effect of the intermediate products on the viscosity variations. The liquid-solid products of coal-oil slurries under different conditions are extracted by Hexane, Toluene and Tetrahydrofuran (THF) respectively. The Hexane soluble is defined as oil. The Hexane insoluble and Toluene soluble is defined as asphaltene (A). The Toluene insoluble and THF soluble is defined as preasphaltene (PA). The THF insoluble is composed of unconverted coal and catalyst, which is marked as THFI. The extraction results are shown in

Table 4 The relationship between $\ln \mu_{s}$ and $\frac{1}{T}$

\begin{tabular}{lclll}
\hline Solvent & $t\left({ }^{\circ} \mathrm{C}\right)$ & Equation & Correlation coefficient $\left(R^{2}\right)$ & Note \\
\hline CT & $40-60$ & $\ln \mu_{s}=7.9227 \times 1000 / T-18.016$ & 0.9950 & Linear \\
& $60-100$ & $\ln \mu_{s}=4.5312 \times 1000 / T-7.8134$ & 0.9942 & Linear \\
& $100-280$ & - & - & Nonlinear \\
FCC & $70-100$ & $\ln \mu_{s}=5.223 \times 1000 / T-8.4319$ & 0.9987 & Linear \\
& $100-300$ & $\ln \mu_{s}=2.3766 \times 1000 / T-8.4319$ & 0.9768 & Linear \\
\hline
\end{tabular}




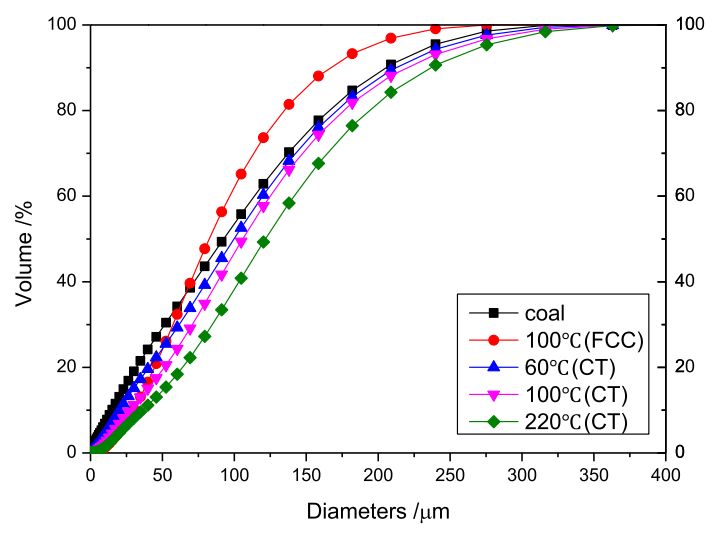

Fig. 7 Particle size integral distribution of coal particles under different conditions

Table 5. It can be seen that the yields of asphaltene and preasphaltene do not show a maximum at $338{ }^{\circ} \mathrm{C}$.

When $\mathrm{CT}$ is used as the solvent, there is a viscosity peak in Fig. 3. If the asphaltene and preasphaltene play a role in viscosity increasing, the yields of asphaltene and preasphaltene will also appear the maximum at $338^{\circ} \mathrm{C}$ (Yan et al. 2009; Xiao and Zhang 2010). However, there is no maximum between asphaltene and preasphaltene at $338{ }^{\circ} \mathrm{C}$. It means that the asphaltene and preasphaltene do not play a key role in the viscosity changes.

The viscosity variations of coal-oil slurries may be caused by the properties of solvents and coal. Because the oxygen content of coal is up to $15.81 \%$, the coal contains a large number of polar functional groups. The polar functional groups may form hydrogen bonds or other bonding forms in the coal molecules. When the functional groups encountered with polar solvent molecules, they may form more stable hydrogen bonds, so the interactions between coal molecules will be destroyed and result in a large swelling ratio of the coal. The oxygen content of CT is $1.86 \%$, which is mainly in the form of phenolic hydroxyl groups, so CT is a polar solvent. When CT is used as the solvent, there may be a larger swelling ratio of the coal than that FCC used as the solvent. In order to confirm this inference, the particle size distribution of coal particles (THFI) at 320,338 , and $390{ }^{\circ} \mathrm{C}$ was analyzed respectively. The results are shown in Fig. 8. At the beginning, the particle size becomes larger than original coal particles

Table 5 The extraction results of liquid-solid products (liquid-solid products basis)

\begin{tabular}{lllrll}
\hline Solvent & Temperature $\left({ }^{\circ} \mathrm{C}\right)$ & Oil $(\%)$ & A $(\%)$ & PA $(\%)$ & THFI $(\%)$ \\
\hline CT & 320 & 36.28 & 11.68 & 18.95 & 33.10 \\
CT & 338 & 38.58 & 9.90 & 23.01 & 28.51 \\
CT & 390 & 38.70 & 16.25 & 33.42 & 11.63 \\
FCC & 450 & 65.02 & 1.57 & 28.37 & 5.03 \\
\hline
\end{tabular}

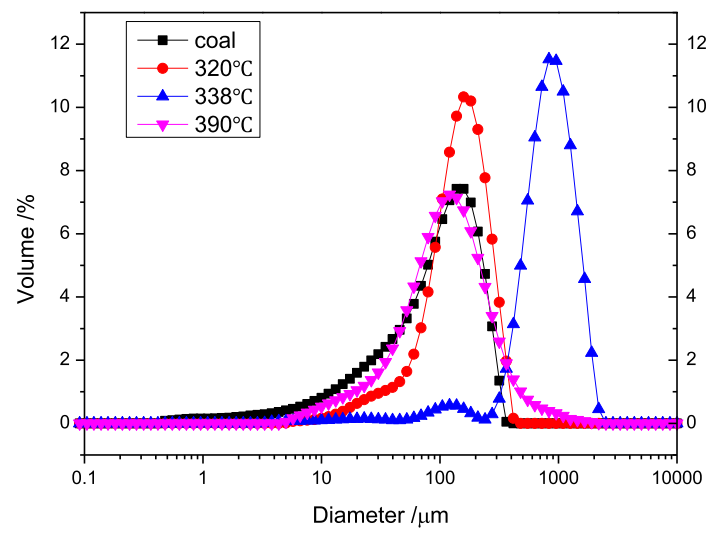

Fig. 8 The particle size of coal particles after hydrogenation reaction

with temperature increasing. When temperature is up to $338{ }^{\circ} \mathrm{C}$, the particle size is the largest, and the particle size at $338{ }^{\circ} \mathrm{C}$ is much larger than original coal particles. This is due to the aggregation of coal particles into larger particles (Ren et al. 2011). As temperature continues to rise, the polar functional groups of the coal are removed, and the skeleton of the coal is destroyed, which result in a decrease in particle size and volume fraction of coal particles. The oxygen content of FCC is $0.22 \%$, so it can be seen a nonpolar solvent. There are little interactions between nonpolar solvent and coal molecules, so the swelling ratio of the coal is smaller than $\mathrm{CT}$ as the solvent (Chang et al. 2005).

\section{Conclusions}

The viscosity variations of coal-oil slurries during heating at high pressure were studied by self-developed viscosity measuring device. It is found that the viscosity of coal-oil slurries varies differently with different solvents as temperature increasing. When FCC is used as the solvent, the viscosity of coal-oil slurry generally decreases with temperature increasing. However, when CT is used as the solvent, the viscosity of coal-oil slurry appears a viscosity peak at $338{ }^{\circ} \mathrm{C}$. It is found that the properties of solvents and coal are the main influencing factors causing the viscosity changes of coal-oil slurries. Because the coal samples contained a large number of polar functional groups, the swelling ratio of coal in polar solvent (CT) was larger than in nonpolar solvent (FCC). The aggregation of coal particles result in the appearance of a viscosity peak. It is also found that when temperature is less than $100{ }^{\circ} \mathrm{C}$, the viscosity variations of coal-oil slurry are caused by the solvent molecules entering into the coal pores. However, when temperature is more than $100{ }^{\circ} \mathrm{C}$, the viscosity variations of coal-oil slurry are mainly caused by the increase of particle size of coal particles. 
Acknowledgement This work is supported by the International S\&T Cooperation Program (2013DFA61660), and the Technology Innovation Fund of CCRI (2016CX01).

Open Access This article is distributed under the terms of the Creative Commons Attribution 4.0 International License (http://crea tivecommons.org/licenses/by/4.0/), which permits unrestricted use, distribution, and reproduction in any medium, provided you give appropriate credit to the original author(s) and the source, provide a link to the Creative Commons license, and indicate if changes were made.

\section{References}

Chang HY, Han WY, Zhang DX et al (2005) Study on thermally dissolved product changes of coal-oil slurry during direct coal liquefaction. J China Coal Soc 30:90-94

Deng CR, Mornoml H, Sanada Y (1987) Effect of preasphaltene solubility an apparent viscosity of coal slurry during high pressure liquefaction. In: 1987 international conference on coal science, Elsevier Science Publishers B V, Amsterdam, Maastricht, pp 315-318

Deng CR, Nio T, Sanada Y et al (1989) Relationship between swelling of coal particles and apparent viscosity of slurry during coal liquefaction for Akabira coal/creosote oil slurry system. Fuel 68:1134-1139

Gao SS, Zhang XW, Li KJ (2015) Study on co-processing of Xinjiang Heishan coal with medium temperature coal tar. Coal Convers 38:40-44

Han WY, Chang HY, Zhang DX et al (2003) Preliminary research on viscosity-temperature characteristic of coal-oil slurry. Coal Convers 26:51-54

Hao LF, Wang YG, Xiong CA et al (2008) Relationship between swelling of coal particles and apparent viscosity of oil-coal slurries. J China Coal Soc 33:80-84

Mooney M (1951) The viscosity of a concentrated suspension of spherical particles. J Colloid Sci 6:162-170
Okutani T, Yokoyama S, Maekama Y (1980) Viscosity of coal paste under high hydrogen pressure. Fuel 59:67-69

Okutani T, Yokoyama S, Maekama Y (1984) Viscosity changes in coal paste during hydrogenation. Fuel 63:164-168

Poling BE (2006) The Properties of Gases and Liquids. Chemical Industry Press, Beijing, Translated by Zhao Hong-ling etc, p 364

Ren YJ, Zhang DX, Gao JS (2011) Viscosity variations of coal-oil slurry under high temperature and high pressure during heating process. Fuel Process Technol 92:2271-2277

Sawatzky H, Farand B, Clelland I et al (1992) Temperature dependence of complexation processes in asphalt and relevance to rheological temperature susceptibility. Symp Div Fuel Chem 37:1407-1436

Shi SD (2012) Engineering foundation of coal hydrotreating. Chemical Industry Press, Beijing, p 153

Tsutsumi A, Yoshida K (1986) Rheological behavior of coal-solvent slurries. Fuel 65:906-909

Wang YG, Hao LF, Xiong CA et al (2007) Apparent viscosity changes of oil-coal slurry during heating at atmosphere. J Fuel Chem Technol 35:513-517

Wu Y, Guo Z, Li KJ, Shi SD et al (2007) Study on measuring viscosity of coal slurry at elevated temperature and high pressures. J Chem Technol 35:754-757

Xiao NY, Zhang RZ (2010) Viscosity changes of Heishan coal-oil slurry at coal direct liquefaction condition. J China Coal Soc 35:1354-1358

Xiong CA, Wang YG, Chen W, Yan Y (2009) Influencing factors for apparent viscosity changes of Shengli coal-oil slurry. J Fuel Chem Technol 37:145-149

Xue YB, Wang ZY, Li BZ et al (2013) Co-processing petroleum catalytic slurry with coal. J Coal Sci Eng 19:554-559

Yan BF, Shi SD, Li WB (2009) The changes and influence factors of viscosity of coal oil slurry in high temperature and high pressure. J China Coal Soc 34:1379-1382

Zhang DJ, Wang F, Li XP et al (2004) Effect of solvent extraction on pore character and granularity of bituminous coal. J Fuel Chem Technol 32:18-22 